\title{
Serious Leisure
}

Saulo Neves de Oliveira*

Johannes Doll

\begin{abstract}
Resumo: Trata-se da resenha do livro Serious Leisure: a perspective for our time, publicado em 2007. Robert A. Stebbins apresenta a "perspectiva do lazer sério", que reúne três formas de lazer: o "lazer sério", o "lazer casual", e o "lazer baseado em projeto". A importância dessa perspectiva nos estudos contemporâneos do lazer é apresentada a partir de estudos que têm sido desenvolvidos em diferentes contextos, dando uma visão geral da produção científica ao leitor. O livro ainda não foi traduzido para o português, mas apresentamos este trabalho como recurso inicial para os interessados nesta perspectiva ainda pouco conhecida no Brasil.
\end{abstract}

Palavras chave: Atividade de lazer. Resenhas de livros.

Serious Leisure: a perspective for our time é uma obra pouco conhecida no Brasil, embora esteja entre aproximadamente 40 livros escritos pelo sociólogo Robert A. Stebbins. Stebbins é professor aposentado da Universidade de Calgary, no Canadá, e iniciou seus estudos sobre o lazer em 1973. Desde 1975, Stebbins tem publicado artigos, capítulos de livro e livros sobre amadores (músicos, atores, jogadores de futebol e beisebol, mágicos, comediantes, arqueologistas e astrônomos), praticantes de hobby (barbershop singers e praticantes de esportes de aventura) e voluntários, especialmente nas comunidades francófonas fora de Quebec (THE SERIOUS LEISURE PERSPECTIVE, 2011).

Desde 2002, Stebbins é responsável por uma seção chamada Leisure Reflection no periódico Leisure Studies Association Newsletter e em 2010, foi eleito membro sênior da World Leisure Academy. Trata-se de um importante pesquisador sobre o lazer, reconhecido mundialmente e com produções científicas relevantes.

\footnotetext{
"Faculdade de Educação. UFRGS. Porto Alegre, RS, Brasil. E-mail: sauloneves@ibest.com.br "UFRGS. Porto Alegre, RS, Brasil. E-mail: johannes.doll@ufrgs.br
} 
Nessa publicação de 2007, reimpressa em 2008, Stebbins se propõe a apresentar uma síntese do que denominou "perspectiva do lazer sério"1 . Como o livro Serious Leisure ainda não foi traduzido para o português, os termos que apresentamos aqui são os mesmos que utilizamos no desenvolvimento da dissertação de mestrado "Lazer Sério e Envelhecimento: loucos por corrida" (OLIVEIRA, 2010).

Consideramos o conceito de "lazer sério" um dos mais instigantes no livro merecedor da atenção dos leitores brasileiros. "Lazer sério" foi a tradução que adotamos para o termo serious leisure, a mesma utilizada no artigo de Costa (2005) para analisar praticantes de esportes na natureza. Também encontramos no trabalho de Teixeira (2008), sobre os participantes da organização de uma festa folclórica no município de São Luíz, Maranhão, que utiliza o "lazer sério" de Stebbins como conceito básico para entender o fenômeno pesquisado. Lacerda e Veiga (2008) utilizam o mesmo conceito para ampliar as discussões entre as relações do profissional do lazer com o marketing. E na tese de doutorado de Stadnik (2008), na Universidade do Minho, utilizando o termo "lazer sério" como um dos conceitos que perpassam a formação de docentes da educação física.

O conceito de "lazer sério" nasceu entre 1973 e 1976, quando Stebbins (2008, p.101) coletava dados para uma pesquisa sobre amadores e profissionais. "Isso não é como o que as pessoas fazem por lazer", contou um jogador amador de beisebol. A partir de uma série de respostas como essa, o pesquisador mudou a direção de sua pesquisa, tentando entender as práticas destes participantes que se recusavam a considerar suas práticas um lazer. Diziam que as atividades que praticavam não poderiam ser um lazer, pois havia um alto comprometimento de sua parte, estavam determinados a alcançar altas performances e se empenhavam ao máximo no desenvolvimento de suas habilidades. Tratava-se de "algo sério" (STTEBINS, 2008, p.101).

Stebbins propôs o termo "lazer sério", considerando-o mais adequado, pois se aproximava das falas de esportistas amadores entrevistados sobre suas atividades. Até então, os conceitos clássicos

${ }^{1}$ serious leisure perspective.

Movimento, Porto Alegre, v. 18, n. 01, p. 325-338, jan/mar de 2012. 
e dominantes que eram utilizados se referiam ao lazer como "um tempo de fruição", longe da seriedade e comprometimento expressos pelos participantes da pesquisa.

Com o passar do tempo, Stebbins desenvolveu conceitualmente outras duas formas de lazer: o "lazer casual" e o "lazer baseado em projeto"2. Estas três formas constituem o que ele chamou de "perspectiva do lazer sério", um enquadramento teórico para as atividades. Embora a Perspectiva englobe estas três formas de lazer, a primeira forma, a do "lazer sério" foi considerada o carro-chefe, não por ter mais importância, mas por ter sido a geradora de questionamentos que levaram ao desenvolvimento teórico das outras duas formas de lazer.

O nome "lazer sério" pode gerar confusão, pois está tanto no título da Perspectiva, quanto no título dado à primeira forma de lazer que a constitui. Arepetição deve-se à familiaridade do meio acadêmico com o termo, pois o período de estudos destinado a esta forma de lazer foi maior.

O desenvolvimento das idéias sobre o "lazer sério" ocupa lugar central no livro, conforme já justificado. Stebbins define o "lazer sério" como sendo:

[...] a prática sistemática de uma atividade por amadores, praticantes de hobby ou voluntários, considerada substancial, interessante e realizadora que em casos típicos, lança-lhes numa carreira (de lazer) centrada na aquisição e expressão de uma combinação de habilidades especiais, conhecimento e experiência (modificado de STEBBINS, 1992, p.3, apud STEBBINS 2008, p.5, tradução nossa).

"Seis qualidades distintivas" ajudam a definir o lazer sério destes praticantes. A "perseverança" é a primeira qualidade apresentada. Refere-se à necessidade ocasional de persistência por parte dos praticantes do lazer sério, como em casos em que o time passa por uma temporada de fracassos, ou em que o voluntário passa por uma situação de constrangimento em suas atividades.

${ }^{2}$ casual leisure e project-based leisure, respectivamente.

Movimento, Porto Alegre, v. 18, n. 01, p. 325-338, jan/mar de 2012. 
A "perseverança" é considerada o motor da qualidade identificada como "carreira". O conceito de "carreira" se refere a uma "carreira subjetiva", opondo-se a uma idéia de "carreira objetiva". Geralmente a idéia de carreira traz consigo valores relacionados a uma progressão no trabalho, porém, no caso da Perspectiva, a "carreira" está ligada a continuidade na atividade, tanto em períodos de aumento de prestígio e benefícios, quanto na diminuição destes.

A continuidade no "lazer sério" se apóia na terceira qualidade: o "esforço". O praticante do "lazer sério" necessita esforçar-se, empenhando e desenvolvendo seu conhecimento, treino, experiência ou habilidades. A quarta qualidade é a presença de "benefícios duráveis" e reúne benefícios de ordem emocional e social, identificados em maior parte entre os amadores.

Como quinta qualidade, o "ethos único", ou "mundo social específico", que se desenvolve em torno das outras qualidades. $\mathrm{O}$ ethos é entendido como o espírito dos participantes da comunidade do "lazer sério", manifestado por suas atitudes compartilhadas, práticas, valores, objetivos e assim por diante. Em torno dessas cinco qualidades distintivas apresentadas, se desenvolve a sexta qualidade que é a "identificação" entre os participantes do "lazer sério".

Uma série de elementos coloca em discussão as relações entre os participantes dentro do "lazer sério". No "lazer sério", existe uma relação entre custos e benefícios, e, de acordo com o pesquisador, esta relação se constitui na "moeda psicossocial" do "ethos único". Em um lado, as "recompensas" ou "premiações" que podem ser pessoais, como o desenvolvimento de habilidades, conhecimento e dos selves (STEBBINS, 2008, p.14), ou, recompensas sociais, que envolvem a participação de um mundo social específico da atividade, associando-se a outros participantes, ajudando no desenvolvimento do grupo, sentindo-se parte necessária do grupo.

No outro lado da moeda estão os custos, entendidos como específicos de cada atividade. Entretanto, os custos são considerados em geral como desapontamentos, desgostos e tensões que se apresentam no desenvolvimento das atividades do "lazer sério". 
Estes componentes psicossociais dão ao "lazer sério" a propriedade de "incontrolabilidade" ou "descontrole" (STEBBINS, 2008, p.18), expressa pelos praticantes quando empenham dinheiro e/ou tempo além do disponível para desenvolvimento de suas atividades de "lazer sério". Ele exemplifica com praticantes que compram os melhores equipamentos para as atividades ou que buscam por renomados professores.

O "lazer casual" e o "lazer baseado em projeto" são as outras formas de lazer identificadas. Como um conceito, "lazer casual" acompanha o surgimento teórico do "lazer sério", porém, apenas a partir dos anos 90 que passou a ter uma atenção acadêmica. Inicialmente se considerava "lazer casual" como "todo o lazer não classificado como de amadores, praticantes de hobby ou voluntários" (STEBBINS, 2001b, p.305 apud STEBBINS, 2008, p.43), porém esta concepção foi revista e reformulada.

$\mathrm{O}$ "lazer casual" foi fortemente utilizado nas publicações iniciais como forma de facilitar o entendimento do "lazer sério". Essa forma de apresentar o "lazer sério", a partir do contraste com o "lazer casual", trouxe consequiências negativas ao entendimento do "lazer casual". Houve uma depreciação do "lazer casual", em oposição ao lugar de destaque dado a participantes que "eram mais do que meros jogadores", escreve Stebbins (2008, p.38, tradução nossa).

"Lazer casual é uma atividade imediata, de valor intrínseco, com satisfação relativamente curta, que requer pouca ou nenhuma habilidade especial para ser aproveitada" (STEBBINS, 2008, p.38, tradução nossa). Oito tipos de atividades foram considerados "lazer casual": jogo, relaxamento, entretenimento passivo, entretenimento ativo, conversação social, estimulação sensorial, voluntariado casual e atividades aeróbicas.

Todas as atividades do "lazer casual" compartilham do hedonismo, ou seja, todas produzem um significante nível de prazer a contentamento para os participantes. "Prazer" e "contentamento" descrevem o "lazer casual", em oposição à "realização" e "recompensa", que servem como descritores dos benefícios 
percebidos pelos participantes do "lazer sério". Além disso, o componente "diversão" que, mesmo estando presente nas duas formas de lazer, é proeminente no "lazer casual".

Com a participação no "lazer casual", pode se originar o desenvolvimento e a manutenção de relacionamentos interpessoais. A "conversação social" parece ser o tipo mais fecundo deste benefício dentre as atividades de "lazer casual". Por fim, o "bem-estar" é outro benefício do engajamento no "lazer casual". Stebbins acredita que este bem-estar está relacionado a um estilo de vida que harmoniza o "lazer sério" e o "lazer casual".

Para discutir a relação entre as práticas de "lazer sério" e "casual", Stebbins utiliza o conceito de optimal leisure lifestyle (2008, p.42). Não encontramos o equivalente no contexto brasileiro, porém, encontramos o conceito estilo de vida óptimo de ócio (STEBBINS, 2000, p.109), em um artigo espanhol. Encerrando a discussão do "lazer casual", Stebbins apresenta dados de outros autores que, ao pesquisarem sobre o "lazer casual", desenvolveram considerações importantes para a Perspectiva.

A terceira forma é o "lazer baseado em projeto" e apareceu no contexto acadêmico em uma publicação de $2005^{3}$. A definição do autor para "lazer baseado em projeto" é

a tarefa criativa, excepcional ou ocasional, pouco freqüente, no tempo livre, que requer planejamento e esforço consideráveis e algumas vezes, habilidades e conhecimento, mas em que, diferente do "lazer sério", não há intenção pelos participantes em se desenvolver nisso [ou melhor, nessas qualidades presentes] (STEBBINS, 2008, p.43, tradução nossa).

O "ocasional" é utilizado para caracterizar tarefas relacionadas a ocasiões regulares como aniversários, festas de fim-de-ano, festivais religiosos, etc. "Criativa" aponta para o resultado da tarefa

${ }^{3}$ STEBBINS, R.A.. Project-based leisure: theoretical neglect of a common use of free time. Leisure Studies, n. 24, p.1-11, 2005. 
que é algo realmente novo ou diferente, expressando a imaginação e talvez conhecimentos rotineiros dos participantes.

"Excepcional" na definição do "lazer baseado em projeto" inclui eventos que ocorrem excepcionalmente, como alguns eventos esportivos, aniversários surpresa, festas de confraternização, etc. Nesta forma de lazer, há o desenvolvimento de um tipo rudimentar de mundo social em torno do projeto, envolvendo amigos, vizinhos, familiares, etc.

A partir da definição de "excepcional" e "ocasional", os projetos são classificados em "projetos excepcionais" e "projetos ocasionais"4. Nos "projetos excepcionais", as pessoas se utilizam de talentos e conhecimento que estão à mão, podendo buscar instruções em livros ou outras fontes de informações. O objetivo do participante é o de cumprir a tarefa e nada mais.

Os "projetos ocasionais" ocorrem de forma freqüente, em virtude de um evento que se repete com uma frequiência determinada (anual, mensal, em estação do ano determinada, etc.). Uma festa religiosa ou folclórica que é realizada anualmente pode ser considerada um exemplo de "projeto ocasional". Estes tipos de projetos possuem uma forte possibilidade de rotina em alguns procedimentos, especialmente quando a criação de uma forma de fazer as coisas causa tamanha satisfação que se torna uma fórmula para os próximos projetos.

Stebbins ressalta que há no "lazer baseado em projeto" a possibilidade de que participantes se sintam fortemente atraídos a buscarem um "lazer sério", a partir do desenvolvimento de uma "carreira". O pesquisador deixa claro, ao final da apresentação das formas de lazer, que entende o nível de complexidade do "lazer sério" em oposição ao do "lazer casual", como "dois pólos opostos em um continuum" (STEBBINS, 2008, p.49, tradução nossa) no qual o "lazer baseado em projeto" está entre os outros dois, quanto ao seu grau de complexidade.

${ }^{4}$ One-shot Projects (STEBBINS, 2008, p.46) e Occasional Projects (STEBBINS, 2008, p.47).

Movimento, Porto Alegre, v. 18, n. 01, p. 325-338, jan/mar de 2012. 
Após apresentar as formas de lazer, Stebbins volta-se a discussão e síntese dos principais conceitos utilizados, buscando auxiliar no entendimento da Perspectiva. Estes conceitos estão organizados em nas categorias: (1) organização (grupos, associações, mundo social, etc.); (2) comunidade (família; trabalho; gênero; classe social; contribuições, incluindo sociedade civil e envolvimento dos cidadãos, e capital social; desvio); (3) história; (4) estilo de vida (incluindo o comprometimento do tempo e o optimal leisure lifestyle); e (5) cultura (comprometimento, obrigação, valores).

Finalizando, o autor trata das pesquisas que foram feitas com base na Perspectiva, entendida como uma Teoria Fundamentada, com possibilidades, limites e vantagens, porém de importância global na contemporaneidade. Stebbins apresenta diferentes estudos nas áreas de turismo, etnia, qualidade de vida e bem-estar, educação para o lazer, gênero, aposentadoria e desemprego, educação de adultos e aprendizagem individual, necessidade especiais, biblioteconomia e ciências tecnológicas, entretenimento e cultura popular.

Para Stebbins, estes estudos deram novos rumos a Perspectiva e, de forma dramática direcionaram aspectos constitutivos para outros campos de pesquisa, criando a expectativa de investigações sobre aspectos presentes em cada uma das formas de lazer e do surgimento de novas formas de lazer, que possam ser incluídas entre as três formas já identificadas.

Em nível global, há muitos desafios na tentativa de ajuste da "perspectiva do lazer sério", especialmente no que diz respeito às características das formas de lazer em países considerados de primeiro e terceiro mundo. O "lazer sério" é considerado uma forma elitista de lazer e o "lazer voluntário", uma forma que assume sentidos diferentes para os países considerados de terceiro mundo.

Bramante (2004, apud STEBBINS, 2008, p.127) é um dos pesquisadores mencionados no livro por seu trabalho com o voluntariado de jovens em Sorocaba, no Brasil. Seu trabalho apóia a idéia de haver amplas possibilidades de pesquisas com a Perspectiva 
em contextos sociais diversos. Cabe indicar aqui a utilização do termo "lazer levado a sério", para "lazer sério", por Bramante em seu projeto de voluntariado no Brasil.

A leitura de Serious Leisure é bastante tranqüila, pois apresenta uma linguagem de fácil entendimento. Entretanto, leitor brasileiro poderá se surpreender com a forma de apresentação da "perspectiva do lazer sério" que é diferente das publicações tradicionalmente encontradas no Brasil. Stebbins procura nesse livro sintetizar a sua vasta obra em apenas um livro e se utiliza de uma série de classificações e hierarquias.

Obviamente, muitos detalhes são deixados de lado, o que faz com que o leitor necessite buscar em publicações anteriores essas informações. Entretanto, novos detalhes e elementos são acrescentados e reorganizados, por conta dos avanços no desenvolvimento dos conceitos e a rápida publicação por parte do autor.

Resumindo, uma leitura de Serious Leisure propicia o conhecimento de uma proposta teórica consistente, elaborada durante décadas, com contribuições interessantes para discussões atuais do campo do lazer. Coloca-se, então, a pergunta, por que Stebbins é um autor tão pouco conhecido no Brasil? Podemos pensar em duas linhas de resposta, uma que aponta mais para as circunstâncias em que os estudos do lazer se desenvolveram no Brasil, uma segunda que encontra no próprio modelo aspectos que dificultam sua compreensão e absorção.

A primeira linha aponta mais para aspectos circunstanciais. Entre estes podemos citar que os estudos do lazer constituem um campo relativamente novo no Brasil. Mesmo existindo trabalhos que datam do início do século XX, foi somente a partir dos anos 80 que uma produção mais ampla e consistente no campo da recreação/ lazer passou a existir (PEIXOTO, 2007). Junta-se a isso o fato de que a introdução e ampliação da discussão do lazer foram intensificadas por organizações como SESC e SESI, buscando fundamentação para suas atividades mais por autores que abordam 
a questão do lazer de forma abrangente, como, por exemplo, Dumazedier, cujo pensamento exerceu forte influência nos estudos de lazer no Brasil (GOMES, 2008). Esta linha de pensamento percebe o lazer como contraposição ao trabalho. Enquanto no mundo do trabalho prevalece a vontade alheia que prescreve e determina ao trabalhador suas atividades, o mundo de lazer é visto como um espaço de liberdade, onde se pode fazer o que se bem entende. Desta forma, o lugar de uma posição teórica já estava, de certa forma, "ocupada" por um pensamento que convenceu pela lógica da contraposição entre trabalho e lazer.

Mas não somente as circunstâncias podem explicar o baixo grau de conhecimento de Robert A. Stebbins e sua teoria do "lazer sério" no Brasil. A própria proposta possui características que podem dificultar sua aceitação, dos quais queremos destacar dois aspectos.

O primeiro se refere ao fato que a teoria de Stebbins se encontra, de certa forma, na contramão de discussões atuais no campo do lazer. Por um lado, existe a já referida contraposição de trabalho e lazer. Em relação a este ponto, a "teoria do lazer sério" introduz ao campo do lazer elementos considerados pertencentes ao mundo de trabalho como dedicação, esforço máximo, repetição, treinamento, carreira, seriedade. Para uma visão de lazer como espaço de liberdade e de certa ludicidade e leveza, estes elementos se tornam de difícil assimilação.

Outro foco de discussão, trazido por Zygmunt Baumann (2001), de que as sociedades atuais estejam marcadas por uma perspectiva de não-estabilidade, expresso por ele pela idéia de "líquido", também se opõem a um modelo teórico que fala do compromisso, da dedicação e da continuidade.

A segunda dificuldade de lidar com a teoria de Stebbins é conceitual. A expressão "lazer sério" no contexto da teoria de Stebbins aparece, na verdade, em dois contextos diferentes. Por um lado, a teoria como toda se chama "perspectiva do lazer sério", por outro lado, das três subdivisões do lazer que Stebbins faz, uma também se 
chama "lazer sério", ao lado do "lazer casual" e "lazer baseado em projetos". É necessária uma leitura atenta para compreender a teoria sem criar confusão, fato que não facilita necessariamente sua aceitação.

Outro elemento que ajuda a compreender o silêncio na literatura brasileira sobre a teoria de Stebbins certamente é o fato de que seu modelo possui seu valor explicativo forte em relação a um tipo de lazer, que até hoje ainda não chamou muito a atenção dos pesquisadores brasileiros, um lazer praticado com uma dedicação, intenção e frequência que vai muito além do que a grande maioria da população realiza. E, finalmente, o próprio fato que ainda não existe uma tradução dos textos de Stebbins no português também restringe seu acesso àqueles que dominam o inglês.

Estes fatores explicam, porém, não justificam a pouca atenção que a teoria de Stebbins encontrou no Brasil. A "perspectiva do lazer sério" possui certas restrições a respeito do campo amplo e diverso de lazer/recreação e não se trata de uma teoria geral que consegue explicar tudo. Por outro lado, ela oferece elementos explicativos excelentes para determinadas formas de lazer.

Por isso, entendemos que essa obra oferece elementos importantes nos debates do lazer e suscita questões pertinentes para avanços na área. Além disso, a Perspectiva evidencia formas de lazer muitas vezes deixadas de lado nas análises ou pouco exploradas ainda, como os sentidos da seriedade nas práticas de lazer. Uma posição central que amplia as possibilidades de análise das pesquisas sobre atividades praticadas em um tempo-espaço de lazer que se situam fora de visões clássicas de lazer.

O presente trabalho, além de apresentar uma obra com potente contribuição científica, faz-nos refletir sobre o desconhecimento e ausência de produções de autores como Stebbins no contexto brasileiro, apontando para necessidade de uma revisão crítica da vasta produção científica sobre lazer no Brasil. Dessa forma, não defendemos uma apropriação direta de sua produção, mas o 
conhecimento e possível crítica de mais um autor que, mesmo sendo já conhecido em contexto europeu e norte-americano, tem poucas inserções na America Latina.

Acreditamos ser importante que a comunidade acadêmica brasileira seja agraciada com uma versão em português e conheça a Perspectiva. Entendemos que este é um livro importante para pesquisadores brasileiros, pois aponta para potenciais contribuições em pesquisas sobre o lazer. Entender a Perspectiva e buscar novas leituras do lazer no contexto brasileiro é o grande desafio que emerge a partir da leitura de Serious Leisure. 
Serious leisure: a perspective for our time Abstract: This is the book review of Serious Leisure: a perspective for our time, published in 2007. Robert A. Stebbins presents the "serious leisure perspective", which includes three forms of leisure: the "serious leisure", "casual leisure " and "project-based leisure." The importance of this perspective in contemporary studies of leisure is presented from studies that have been developed in different contexts, giving an overview of the scientific to the reader. The book has not yet been translated into Portuguese, but we present this work as initial resource for those interested in this perspective still little known in Brazil.

Keywords: Leisure activities. Book reviews.

\section{Serious leisure: a perspective for our time}

Resúmen: Esta es la reseña del libro Serious Leisure: a perspective for our time, publicado en 2007. Robert A. Stebbins presenta la "perspectiva de ocio serio", que incluye tres formas de ocio: el "ocio serio", "ocio casual" y ocio proyecto-basado". La importancia de esta perspectiva en los estudios contemporáneos de ocio se presenta de estudios que se han desarrollado en contextos diferentes, dando una visión general de la producción científica. El libro aún no se ha traducido al portugués, pero se presenta ese trabajo como recurso inicial para aquellos interesados en esta perspectiva poco conocida en Brasil.

Palabras-clave: Actividades recreativas. Reseña de libros.

\section{REFERÊNCIAS}

BAUMANN, Zygmunt. Modernidade Líquida. Rio de Janeiro: Jorge Zahar, 2001.

COSTA, Vera Lúcia de Menezes. Jogos com Limites e Incertezas: a aventura e o risco de esportistas na montanha. Corpus et Scientia, Rio de Janeiro. v. 1, n. 2, p. 17-29, 2005.

GOMES, C. M. Dumazedier e os Estudos do Lazer no Brasil: Breve Trajetória Histórica. In: SEMINÁRIO LAZER EM DEBATE, 9, 2008. Anais. São Paulo, USP/ Leste-CELAR/UFMG, 2008.

Movimento, Porto Alegre, v. 18, n. 01, p. 325-338, jan/mar de 2012. 
LACERDA, Leonardo Lincoln Leite; VEIGA, Ricardo Teixeira. Museu e Marketing: elementos para a formação/atuação dos profissionais do lazer? Revista Brasileira de Ciências do Esporte, Campinas. v. 29, n. 3, p. 57-74, 2008.

OLIVEIRA, Saulo Neves. Lazer Sério e Envelhecimento: loucos por corrida. 101 f. Dissertação (Mestrado) - Programa de Pós-Graduação em Educação, UFRGS, Porto Alegre, 2010.

STADNIK, Adriana Maria Wan. Representações e práticas de professores universitários de educação física : quatro histórias de vida. 486 f. Tese (Doutorado) - Instituto de Estudos da Criança, Universidade do Minho, Braga, 2008.

STEBBINS, Robert A. Serious Leisure: a perspective for our time. New Jersey: Transaction, 2008. 156f.

STEBBINS, Robert A. Un Estilo de Vida Óptimo de Ócio: combinar ocio serio y casual en la búsqueda del bienestar personal. In: CUENCA CABEZA, Manuel. (Ed.). Ocio y desarrollo humano. Bilbao: Instituto de Estudios de Ocio de la Universidad de Deusto/ World Leisure, 2000. p.109-116.

TEIXEIRA, Heraldo Marconi da Costa. A Festa do Bumba-Meu-Boi da Maioba na Configuração do Estilo de Vida e Lazer. 135 f. Dissertação (Mestrado) Programa de Pós-Graduação em Ciências da Motricidade, UNESP, Rio Claro, 2008.

THE SERIOUS LEISURE PERSPECTIVE. Biography of Robert A. Stebbins. Canadá, 2011. Disponível em:< http://www.seriousleisure.net/biography-of-robert-astebbins.html >. Acesso em: 19 set. 2011. 
